\title{
BMJ Open The effect of the National Essential Medicines Policy on health expenditures and service delivery in Chinese township health centres: evidence from a longitudinal study
}

\author{
Xin Zhang, ${ }^{1}$ Qunhong Wu, ${ }^{1}$ Guoxiang Liu, ${ }^{1}$ Ye Li, ${ }^{1}$ Lijun Gao, ${ }^{1}$ Bin Guo, ${ }^{1}$ \\ Wenqi Fu, ${ }^{1}$ Yanhua Hao, ${ }^{1}$ Yu Cui, ${ }^{1}$ Weidong Huang, ${ }^{1}$ Peter C Coyte ${ }^{2}$
}

To cite: Zhang $X, W u$, Liu G, et al. The effect of the National Essential Medicines Policy on health expenditures and service delivery in Chinese township health centres: evidence from a longitudinal study. BMJ Open 2014:4:e006471.

doi:10.1136/bmjopen-2014006471

- Prepublication history for this paper is available online. To view these files please visit the journal online (http://dx.doi.org/10.1136/ bmjopen-2014-006471).

ZX, LG and BG contributed equally to this paper.

Received 26 August 2014 Revised 17 November 2014 Accepted 1 December 2014

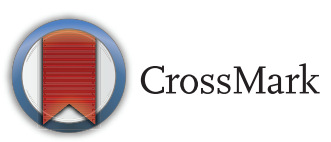

${ }^{1}$ Harbin Medical University, Harbin, China

${ }^{2}$ University of Toronto,

Toronto, Canada

Correspondence to

Dr Qunhong Wu;

wuqunhong@163.com and

Dr Guoxiang Liu;

Igx6301@163.com

\section{ABSTRACT}

Objectives: The government of China has introduced a National Essential Medicines Policy (NEMP) in the new round of health system reform. The objective of this paper is to analyse whether the NEMP can play a role in curbing the rise of medical expenditures without disrupting the availability of healthcare services at township hospitals in China.

Design: This study adopted a pre-post treatmentcontrol study design. A difference-in-differences method and fixed-effects model for panel data were employed to estimate the effect of the NEMP.

Setting: Chongqing, Jiangsu and Henan Province, in China, in 2009 and 2010.

Participants: 296 township health centres. Outcome measures: Outcomes for health expenditures were average outpatient drug expenses per visit, average inpatient drug expenses per discharged patient, average outpatient expenses per visit and average inpatient expenses per discharged patient. Outcomes for care delivery were the numbers of visits per certified doctor per day and the numbers of hospitalised patients per certified doctor per day.

Results: The township health centres that were enrolled in the NEMP reported $26 \%(p<0.01)$ lower drug expenditures for inpatient care. An $11 \%(p<0.05)$ decrease in average inpatient expenditures per discharged patient was found following the implementation of the NEMP. The impacts of the NEMP on average outpatient expenditures and outpatient drug expenditures were not statistically significant at the $5 \%$ level. No statistically significant associations were found between the NEMP and reduction in quantity of health service delivery.

Conclusions: The NEMP was significant in its effect in reducing inpatient medication and health service expenditures. This study shows no evidence that the quantity of healthcare service declined significantly after introduction of the NEMP over the study period, which suggests that if appropriate matching policies are introduced, the side effects of the NEMP can be counteracted to some degree. Further research including a long-term follow-up study is needed.

\section{Strengths and limitations of this study}

- We used the difference-in-differences method to evaluate the effect of the NEMP. The strongest quasi-experimental approach permits the rigorous evaluation of causal impacts.

- The fixed-effects model for panel data was used to control the unobserved time-invariant heterogeneity.

- This study only examined the short-term effect of the NEMP. The long-term effect should be followed up in future research.

\section{INTRODUCTION}

In the last three decades, driven by extensive market-oriented economic reforms, there have been tremendous changes to the Chinese healthcare system. Public hospitals have been transformed from quasi-governmental agencies into enterprise-like entities with greater autonomy. At the same time, government funding for public hospitals has moved from full cost-based reimbursement to prospective budgeting, with the public sector share of finance falling from $60 \%$ in the 1980 s to $11 \%$ in 2009. ${ }^{2}$ To partially compensate for the shortfall in public finance, a drug mark-up policy was introduced to allow hospitals to earn a $15 \%$ mark-up on the sale of pharmaceutical products. ${ }^{3}$

Propelled by market competition and a policy of greater hospital autonomy, which allowed hospitals to retain residual revenue for capital construction and for employee bonuses and benefits, incentives to generate hospital profits have increased. ${ }^{4}$ Additionally, the policy of differential drug pricing that required low prices for the sale of generic drugs and higher prices for patented drugs gave hospitals an incentive to increase the sale of patented drugs. ${ }^{5}$ Consequently, 
patented drug sales have become an important source of hospital revenues. ${ }^{6}$ On average, these drug sales accounted for $42 \%$ of the total income for public hospitals in $2009 .^{7}$ In township health centres, $60.4 \%$ of outpatient care revenue and $52.9 \%$ of inpatient care revenue were derived from drugs in $2010 .^{7}$

In order to effectively address concerns raised about the current set of market incentives as well as to improve the government's role in healthcare, the Chinese Government launched a new round of health system reforms. One of the key reform initiatives launched in August, 2009, was the National Essential Medicines Policy (NEMP). This policy entailed the establishment of a uniform national essential medicine list (EML) and stipulated a series of policies on drug procurement, tendering, supervision and quality assurance. ${ }^{8}$ The national EML issued in 2009 included 307 generic brand name medicines. Provincial governments were offered the opportunity to supplement the EML according to their specific local situations. With the implementation of the NEMP, effective and inexpensive generic medicines were often likely to win tenders through a unified public bidding process and be included in the EML. Moreover, the drug mark-up policy was cancelled in primary hospitals after implementing the NEMP. As part of the NEMP, a zero-mark-up policy on drug sales was imposed; this change meant that hospitals would no longer earn any profit for prescribing essential drugs. As compensation, local governments increased subsidies to hospitals so as to make up for their loss in revenue. ${ }^{10}$ The NEMP was implemented in primary health institutions in early 2010.

Previous studies showed that the NEMP was associated with a change in the availability and use of essential medicines in primary care facilities. ${ }^{11-13}$ But empirical evidence remains limited in terms of the overall effect of the NEMP on health expenditures and on service delivery because most study designs do not permit the rigorous evaluation of its impact. ${ }^{14-16}$ Consequently, the objective of this paper is to examine the impact of the NEMP on health expenditures and care delivery by using a natural experiment with panel data. To achieve this goal, difference-in-differences (DD) methods in conjunction with fixed-effects (FEs) regression models were employed to compare the impact of the NEMP for township health centres, before and after township health centres began implementing the NEMP.

\section{DATA AND METHODS}

While the NEMP was introduced in 2009, the date when this policy was adopted at specific township health centres varied. This variation in adoption allows for a natural experiment to assess the impact of the NEMP.

This study was conducted in Chongqing, Henan and Jiangsu provinces, which are representative of the western, central and eastern regions of China, respectively. Five counties from each province were randomly selected for study inclusion according to their underlying socioeconomic conditions. Two groups of township health centres were studied: first, township health centres were in the intervention group if they had launched the NEMP in the first quarter of 2010; and second, township health centres were in the control group if they did not introduce the NEMP within 2010. The analysis sample comprised 296 township health centres: 107 in the treatment group and 189 in the control group. This study used two waves of panel data for the sample of 296 township health centres: 2009 (the preintervention year) and 2010 (the postintervention year).

Financial statements of township health centres and local statistical data were collected as shown in table 1 . There are two types of dependent variable in our analysis: first, drug and healthcare expenditures; and second, measures of health service delivery. To estimate the impact of the NEMP on health expenditures, four different sets of expenditure data were used: average outpatient drug expenses per visit; average inpatient drug expenses per discharged patient; average outpatient expenses per visit; and finally, average inpatient expenses per discharged patient. The measures of health service delivery by township health centres used in this study were: the numbers of visits per certified doctor per day; and the numbers of hospitalised patients per certified doctor per day. The control variables were represented by certified doctors, beds and per capita gross domestic product (GDP) as shown in table 1. The dependent variables and the per capita GDP variable

\begin{tabular}{|c|c|}
\hline Variables & Description \\
\hline After & $\begin{array}{l}1 \text { if the time is after the essential } \\
\text { drug policy was implemented, } \\
0 \text { otherwise }\end{array}$ \\
\hline NEMP & $\begin{array}{l}1 \text { if the health centre is in the } \\
\text { intervention group, } 0 \text { otherwise }\end{array}$ \\
\hline NEMP $\times$ After & $\begin{array}{l}1 \text { if the time is after the essential } \\
\text { drug policy and the health centre in } \\
\text { treatment group, } 0 \text { otherwise }\end{array}$ \\
\hline Certified doctors & Numbers of certified doctors \\
\hline Beds & Numbers of beds \\
\hline Log of GDP & $\begin{array}{l}\text { Log of the GDP per capita at } \\
\text { county level }\end{array}$ \\
\hline Outpatient exp & $\begin{array}{l}\text { Log of average outpatient } \\
\text { expenditure of care per visit }\end{array}$ \\
\hline Inpatient exp & $\begin{array}{l}\text { Log of average inpatient expenses } \\
\text { per discharged patient }\end{array}$ \\
\hline Outpatient drug exp & $\begin{array}{l}\text { Log of average outpatient drug } \\
\text { expenditure per visit }\end{array}$ \\
\hline Inpatient drug exp & $\begin{array}{l}\text { Log of average inpatient drug } \\
\text { expenditure per discharge patient }\end{array}$ \\
\hline $\begin{array}{l}\text { Daily visits per } \\
\text { doctor }\end{array}$ & $\begin{array}{l}\text { Average number of visits per } \\
\text { certified doctor per day }\end{array}$ \\
\hline $\begin{array}{l}\text { Daily inpatient stays } \\
\text { per doctor }\end{array}$ & $\begin{array}{l}\text { Average number of inpatients stay } \\
\text { per certified doctor per day }\end{array}$ \\
\hline
\end{tabular}


Table 2 Study sample characteristics

\begin{tabular}{|c|c|c|c|c|c|c|c|c|}
\hline \multirow[b]{3}{*}{ Variables } & \multicolumn{4}{|l|}{2009} & \multicolumn{4}{|l|}{2010} \\
\hline & \multicolumn{2}{|c|}{$\begin{array}{l}\text { Treatment } \\
(n=107)\end{array}$} & \multicolumn{2}{|c|}{ Control $(n=189)$} & \multicolumn{2}{|c|}{$\begin{array}{l}\text { Treatment } \\
(n=107)\end{array}$} & \multicolumn{2}{|c|}{ Control $(n=189)$} \\
\hline & Mean & SD & Mean & SD & Mean & SD & Mean & SD \\
\hline Certified doctors & 15.972 & 11.355 & 15.415 & 14.727 & 16.682 & 11.720 & 15.422 & 13.226 \\
\hline Beds & 32.255 & 23.977 & 33.696 & 27.330 & 35.585 & 25.613 & 34.557 & 23.855 \\
\hline Lngdp & 10.290 & 0.428 & 9.880 & 0.542 & 10.496 & 0.400 & 10.072 & 0.523 \\
\hline Outpatient exp & 3.628 & 0.718 & 3.748 & 0.718 & 3.578 & 0.624 & 3.725 & 0.762 \\
\hline Inpatient exp & 6.949 & 0.584 & 7.012 & 0.650 & 6.975 & 0.547 & 7.145 & 0.631 \\
\hline Outpatient drug exp & 3.180 & 0.783 & 3.271 & 0.757 & 3.064 & 0.683 & 3.263 & 0.787 \\
\hline Inpatient drug exp & 6.314 & 0.589 & 6.451 & 0.655 & 6.239 & 0.575 & 6.634 & 0.619 \\
\hline Daily visits per doctor & 15.197 & 8.376 & 9.908 & 6.787 & 13.512 & 6.350 & 9.589 & 7.019 \\
\hline Daily inpatient stays per doctor & 2.183 & 1.777 & 2.589 & 2.207 & 2.258 & 1.863 & 2.378 & 1.707 \\
\hline
\end{tabular}

were $\log$ transformed as the original data are skewed to the right. Table 2 provides an overview of the characteristics of our study sample stratified by treatment status.

The DD method was employed to compare drug expenditures and health service delivery between treatment and control groups. The DD approach estimates the impact of the NEMP by comparing trends before and after implementation for the group that receives the programme (the treatment group) and the group that does not (the control group). This method allows us to take into account any differences between the treatment and control groups that are invariant over time. ${ }^{17}$ The estimating equation would be specified as follows:

$\mathrm{Y}_{\mathrm{it}}=\beta_{1}+\beta_{2} \mathrm{NEMP}_{\mathrm{i}}+\beta_{3}$ After $_{\mathrm{t}}+\delta\left(\mathrm{NEMP}_{\mathrm{i}} \times \mathrm{After}_{\mathrm{t}}\right)+\mathrm{e}_{\mathrm{it}}$

where $Y_{i t}$ is the observed outcome for township health centre $\mathrm{i}$ in period $\mathrm{t}$; After $\mathrm{t}_{\mathrm{t}}$ is a time indicator variable that equals 1 in the period after the policy change and 0 in the period before the policy change; $\mathrm{NEMP}_{\mathrm{i}}$ is a dummy variable that equals 1 if individual $\mathrm{i}$ is in the treatment group and 0 if the individual is in the control group.

To control the unobserved time-invariant heterogeneity, the following FEs model for panel data was used. ${ }^{18} 19$

$$
\begin{aligned}
\mathrm{Y}_{\mathrm{it}}= & \beta_{1}+\beta_{2} \mathrm{NEMP}_{\mathrm{i}}+\beta_{3} \text { After }_{\mathrm{t}}+\delta\left(\mathrm{NEMP}_{\mathrm{i}} \times \mathrm{After}_{\mathrm{t}}\right) \\
& +\mathrm{c}_{\mathrm{i}}+\mathrm{e}_{\mathrm{it}}
\end{aligned}
$$

where $c_{i}$ is any unobserved characteristics of individual township health centre $\mathrm{i}$ that do not change over time. When we have repeat observations we can eliminate $c_{i}$ by analysing the changes in $Y$ from period 1 to period 2. We obtain the following equation:

$$
\begin{aligned}
\mathrm{Y}_{\mathrm{i} 2}-\mathrm{Y}_{\mathrm{i} 1}= & {\left[\beta_{1}+\beta_{2} \operatorname{NEMP}_{\mathrm{i}}+\beta_{3} 1+\delta\left(\mathrm{NEMP}_{\mathrm{i}} \times 1\right)\right.} \\
& \left.+\mathrm{c}_{\mathrm{i}}+\mathrm{e}_{\mathrm{i} 2}\right]-\left[\beta_{1}+\beta_{2} \mathrm{NEMP}_{\mathrm{i}}+\beta_{3} 0\right. \\
& \left.+\delta\left(\mathrm{NEMP}_{\mathrm{i}} \times 0\right)+\mathrm{c}_{\mathrm{i}}+\mathrm{e}_{\mathrm{i} 1}\right] \\
\Delta \mathrm{Y}_{\mathrm{i}}= & \beta_{3}+\delta \mathrm{NEMP}_{\mathrm{i}}+\Delta \mathrm{e}_{\mathrm{i}}
\end{aligned}
$$

where $\delta$ is the treatment effect of the NEMP.
All regression analyses use robust SEs. Levels of statistical significance used are $5 \%$ and $1 \%$.

\section{RESULTS}

Average drug expenditures and healthcare expenditures

Table 3 shows the estimated effects of the NEMP on the natural logarithm of drug expenditures for outpatients and inpatients. We presented two sets of estimates, one based on ordinary least squares (OLS) regression equations using pooled data and the other based on FE panel data methods.

The results from OLS and FEs estimation approaches show that the coefficients of the DD estimators $($ NEMP $\times$ After $)$ was negative but not statistically significant at the $5 \%$ level in the case of average outpatient drug expenditure. The results of each model suggest that the NEMP was associated with a reduction in average inpatient drug expenditures. Specifically, the DD estimates from the FEs models indicate that the NEMP reduced drug expenditures per discharged patient by $26 \%$ for inpatient care $(p<0.01)$. The coefficients were similar in sign and magnitude in the OLS estimates and the DD methods.

As shown in table 4, the impact of the NEMP on the natural logarithm of average outpatient expenditures per visit was not statistically significant in all the models. In contrast, the estimated coefficients of inpatient expenditures per discharged patient remained negative and significant at the $5 \%$ level in the OLS models. After controlling for the impact of time-invariant unobserved factors, the FEs estimates yield a statistically significant $(p<0.05) 11 \%$ decrease in average inpatient expenditures per discharged patient.

\section{Health service delivery}

We analysed the effect of the NEMP on health service delivery per doctor in township health centres. The results of OLS and FE models showed the same impact of the NEMP on service delivery (table 5). Specifically, daily visits and daily inpatients per doctor were not associated with the adoption of the NEMP. This suggests that 
Table 3 Effect of NEMP on drug expenditures stratified by inpatient and outpatient care

\begin{tabular}{|c|c|c|c|c|c|c|c|c|}
\hline \multirow[b]{2}{*}{ Variable } & \multicolumn{4}{|c|}{ Outpatient drug expenditures } & \multicolumn{4}{|c|}{ Inpatient drug expenditures } \\
\hline & $\overline{\text { OLS }}$ & & FE & & $\overline{\text { OLS }}$ & & FE & \\
\hline NEMP & $-0.091(0.383)$ & $-0.519^{\star *}(0.168)$ & & & $-0.137(0.290)$ & $-0.485^{\star \star}(0.096)$ & & \\
\hline After & $-0.007(0.017)$ & $-0.194^{\star *}(0.034)$ & $-0.007(0.017)$ & $-0.037(0.104)$ & $0.183^{\star \star}(0.038)$ & $0.014(0.044)$ & $0.185^{\star \star}(0.036)$ & $0.200 *(0.084)$ \\
\hline NEMP $\times$ After & $-0.108(0.065)$ & $-0.119(0.058)$ & $-0.108(0.064)$ & $-0.123(0.062)$ & $-0.258^{* *}(0.069)$ & $-0.266^{\star \star}(0.067)$ & $-0.255^{\star \star}(0.067)$ & $-0.258^{\star \star}(0.064)$ \\
\hline Certified doctors & & $0.016^{*}(0.006)$ & & $-0.009(0.004)$ & & $0.007(0.005)$ & & $-0.002(0.004)$ \\
\hline Beds & & $-0.007^{*}(0.003)$ & & $0.000(0.004)$ & & $0.000(0.002)$ & & $0.003(0.003)$ \\
\hline Log GDP & & $1.003^{\star \star}(0.124)$ & & $0.217(0.553)$ & & $0.827^{\star \star}(0.059)$ & & $-0.090(0.297)$ \\
\hline Intercept & $3.271^{\star \star}(0.206)$ & $-6.657^{\star *}(1.215)$ & $3.238^{\star \star}(0.012)$ & $1.172(5.539)$ & $6.451^{* *}(0.168)$ & $-1.830^{\star *}(0.552)$ & $6.400^{\star \star}(0.015)$ & $7.239^{*}(2.963)$ \\
\hline $\mathrm{R}^{2}$ & 0.011 & 0.494 & 0.023 & 0.034 & 0.056 & 0.553 & 0.115 & 0.118 \\
\hline
\end{tabular}

${ }^{*} p<0.05,{ }^{* *} p<0.01$.

Robust SEs in parentheses.

FE, fixed-effects; GDP, gross domestic product; NEMP, National Essential Medicines Policy; OLS, ordinary least squares.

Table 4 Effect of NEMP on total health expenditures by inpatient and outpatient care

\begin{tabular}{|c|c|c|c|c|c|c|c|c|}
\hline \multirow[b]{2}{*}{ Variable } & \multicolumn{4}{|l|}{ Outpatient } & \multicolumn{4}{|l|}{ Inpatient } \\
\hline & $\overline{\text { OLS }}$ & & FE & & $\overline{\text { OLS }}$ & & FE & \\
\hline NEMP & $-0.120(0.359)$ & $-0.502^{\star \star}(0.139)$ & & & $-0.063(0.300)$ & $-0.405^{\star \star}(0.125)$ & & \\
\hline After & $-0.024(0.020)$ & $-0.194^{* *}(0.033)$ & $-0.024(0.020)$ & $-0.064(0.086)$ & $0.133^{\star *}(0.027)$ & $-0.031(0.028)$ & $0.132^{* *}(0.026)$ & $0.017(0.058)$ \\
\hline NEMP $\times$ After & $-0.026(0.047)$ & $-0.042(0.044)$ & $-0.026(0.047)$ & $-0.043(0.042)$ & $-0.108^{*}(0.048)$ & $-0.113^{*}(0.041)$ & $-0.093(0.048)$ & $-0.106^{\star}(0.036)$ \\
\hline Certified doctors & & $0.016^{*}(0.006)$ & & $-0.008(0.005)$ & & $0.014^{*}(0.005)$ & & $-0.003(0.003)$ \\
\hline Bed & & $-0.003(0.002)$ & & $0.002(0.003)$ & & $-0.001(0.002)$ & & $0.004(0.002)$ \\
\hline Log GDP & & $0.890^{\star *}(0.127)$ & & $0.251(0.452)$ & & $0.793^{\star \star}(0.085)$ & & $0.569^{*}(0.202)$ \\
\hline Intercept & $3.749^{\star \star}(0.196)$ & $-5.190^{\star *}(1.234)$ & $3.705^{\star \star}(0.010)$ & 1.222 (4.522) & $7.012^{\star *}(0.185)$ & $-1.001(0.794)$ & $6.988^{\star \star}(0.011)$ & $1.199(2.021)$ \\
\hline $\mathrm{R}^{2}$ & 0.009 & 0.505 & 0.007 & 0.017 & 0.016 & 0.595 & 0.087 & 0.104 \\
\hline
\end{tabular}

${ }^{*} \mathrm{p}<0.05,{ }^{* *} \mathrm{p}<0.01$

Robust SEs in parentheses.

FE, fixed-effects; GDP, gross domestic product; NEMP, National Essential Medicines Policy; OLS, ordinary least squares. 


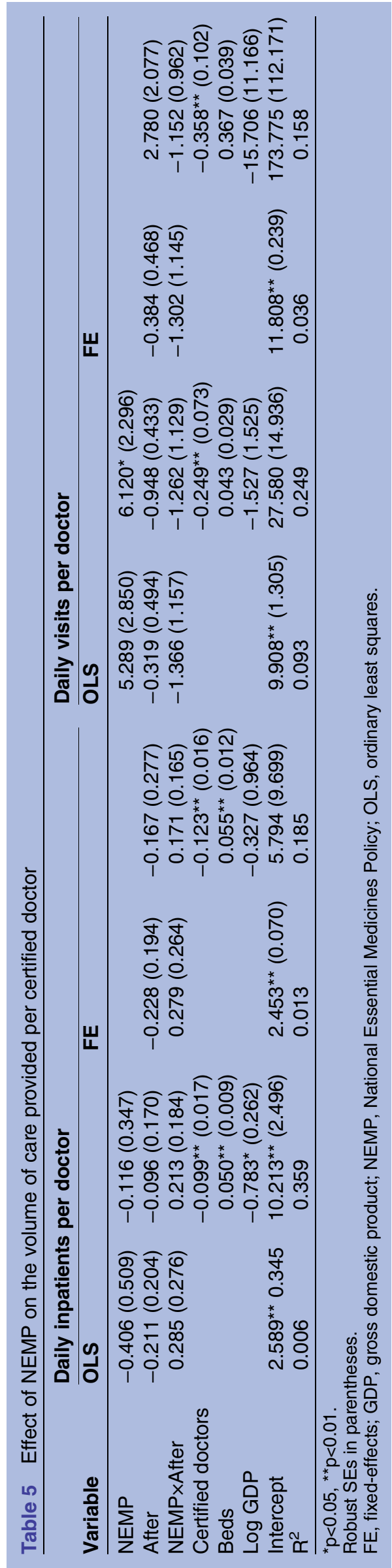

the NEMP did not alter this dimension of healthcare delivery for doctors.

\section{DISCUSSION}

The evidence reported in this paper strongly suggests a causal effect of the drug policy reform on drug expenditures. Specifically, the results demonstrate that the NEMP reduced inpatient drug expenditures by $26 \%$ and total expenditures per admission by $10 \%$.

One potential explanation for the reduced drug and healthcare expenditures at township health centres is the reduction in drug prices. ${ }^{12}$ On the one hand, the zero-mark-up policy is one of the key measures introduced by the NEMP, which ensures that essential medicines are available at procurement cost. On the other hand, the essential medicines are centrally procured through competitive bidding by provincial authorities. This centralised procurement and bidding process simplified the circulation links and improved the procurement efficiency. ${ }^{8}$ The government reported that the price of essential medicines fell by $16.9 \%$ between 2009 and $2011 .^{20}$

Another potential reason for the finding that drug and health expenditures fell after the adoption of the NEMP may be due to changes in the financial structure and incentive mechanisms used in township health centres. The NEMP provided a series of policies and measures rather than pricing regulation in isolation. One of the supportive strategies of the NEMP was in a fundamental change to the financing structure of township health centres. Governments are required to increase financial subsidies in order to make up for the lower revenue from the sale of medications following the implementation of the NEMP. ${ }^{8}$ These increases in government subsidies are used to support the operational costs of township health centres. In the township health centres that implemented the NEMP, the share of governmental subsidies in total revenues doubled from $16.6 \%$ in 2009 to $30 \%$ in 2010 . At the same time, drug revenue as a proportion of total revenues in township health centres that adopted the NEMP fell significantly from $49.2 \%$ in 2009 to $38.6 \%$ in 2010 , while this share was invariant for the control group at about $50 \%$. The increase in government subsidies for hospitals alleviated the heavy dependence of township health centres on drug revenues. The phenomenon of proscribing expensive or potentially unnecessary medications has been inhibited to a certain degree. ${ }^{14}{ }^{21}$ As a result, drug expenditures have fallen.

In addition, it should be noted that the reduced healthcare expenditures may have been associated with a reduction in the availability of some pharmaceutical products. ${ }^{12}$ Since the launch of NEMP, township health centres exclusively used EML drugs. These essential medicines are often insufficient to meet the needs of some complicated clinical treatments. ${ }^{22}$ Furthermore, as these medicines are centrally procured and distributed 
according to strict regulatory control, there are often delays in accessing such drugs. ${ }^{9}$ As a result, some patients with serious illnesses are more likely to be referred to secondary or tertiary hospitals in order to garner access to these essential medicines. ${ }^{15}$

One important question posed in this study was whether the care provided in township health centres was influenced by the NEMP. Many policy-makers and researchers worried that if the incentives to doctors to earn extra money were diminished then their enthusiasm for providing services might lower the quantity as well as quality of service delivery. ${ }^{14}{ }^{15}{ }^{23}$ In contrast to the anticipated negative impact described in the literature and by policy decision makers, this study shows that neither the outpatient nor inpatient care provided by doctors was significantly affected by the introduction of the NEMP during the study period.

One potential explanation for the insignificant impact of the NEMP on healthcare delivery is that physicians have incentives within the current policy setting to maintain care provision. ${ }^{24}$ To stimulate the physicians' initiative, the performance-based salary system was required in primary health facilities that implemented the NEMP. ${ }^{10}$ These performance-based salary systems gradually replaced previous revenue-based bonus systems. This change in the method of physician reimbursement may counteract incentives inherent in the NEMP and thereby leave service delivery unchanged. ${ }^{25-27}$

The analysis outlined in this manuscript is subject to some limitations. First, we used one wave of postintervention data after the introduction of the NEMP. This period has excluded the changes to the national EML and other supporting measures. There is a need to monitor the long-term effects of the NEMP on the containment of healthcare expenditures as well as on health service delivery. Second, because the NEMP was implemented in a staged manner in 2010 and 2011, there is the potential for selection bias whereby those that participated in 2010 might be different than those that joined at later dates. While there is potential for selection bias, the use of FEs models might help to overcome it to some degree, specifically, if unobserved time preference characteristics were constant over time, FEs estimation can overcome the omitted variables problems. ${ }^{19} 28$ Third, the study examined the effect of the NEMP in three provinces in China, so the findings cannot be generalised nationwide. Despite these limitations and the difficulties inherent in evaluation of national medicine policy, our results still have significant policy implications.

\section{CONCLUSION}

In general, the NEMP was associated with significant reductions in inpatient drug expenditures and inpatient healthcare expenditures in township health centres. Consequently, it is suggested that the introduction of the NEMP has played a positive role in containing the rapid increase in pharmaceutical and healthcare expenditures.
The positive evidence could be informative for the implementation of the NEMP in secondary hospitals in China and give reference to countries that seek to develop and implement a national drug policy. The results presented here also suggested that NEMP adoption was not associated with changes to the delivery of healthcare by physicians over the study period. It suggests that improvements in health service efficiency may occur through the adoption of appropriate incentive mechanisms. Further research should be pursued into the far-reaching impact of the NEMP on healthcare spending as well as service delivery in primary health institutions.

Contributors ZX, LG and BG contributed equally to this paper. QW, GL, YH and $Y C$ collected the data; $X Z, Y L, G L$ and $W H$ analysed the data; $X Z$ and $W F$ wrote the draft; PCC, QW and BG contributed to the analysis and interpretation of the study findings and revised the manuscript.

Funding This research received grant from the National Nature Science Foundation of China $(71333003,71373062)$ and Seed Funding of Public Health School of Harbin Medical University.

Competing interests None.

Provenance and peer review Not commissioned; externally peer reviewed.

Data sharing statement No additional data are available.

Open Access This is an Open Access article distributed in accordance with the Creative Commons Attribution Non Commercial (CC BY-NC 4.0) license, which permits others to distribute, remix, adapt, build upon this work noncommercially, and license their derivative works on different terms, provided the original work is properly cited and the use is non-commercial. See: http:// creativecommons.org/licenses/by-nc/4.0/

\section{REFERENCES}

1. Chinese Ministry of Health. 2009 Financial report of medical institutions. Beijing: Chinese Ministry of Health, 2010.

2. Sun $Q$, Santoro MA, Meng Q, et al. Pharmaceutical policy in China. Health Aff 2008;27:1042-50.

3. Meng Q, Cheng G, Silver L, et al. The impact of China's retail drug price control policy on hospital expenditures: a case study in two Shandong hospitals. Health Policy Plan 2005;20:185-96.

4. Hsiao WC, Maynard A. Health economics in China. Foreword. Health Econ 2009;18(Suppl 2):S1-2.

5. Guan X, Liang H, Xue Y, et al. An analysis of China's National Essential Medicines Policy. J Public Health Pol 2011;32:305-19.

6. Zhang $\mathrm{H}$. China's irrational medical pricing scheme. Lancet 2010;375:726.

7. Chinese Ministry of Health. 2010 Chinese health statistical digest. Beijing: Chinese Ministry of Health, 2011.

8. Barber SL, Huang B, Santoso B, et al. The reform of the essential medicines system in China: a comprehensive approach to universal coverage. J Glob Health 2013;3:010303.

9. Hu S. Essential medicine policy in China: pros and cons. J Med Econ 2013;16:289-94.

10. Chinese Ministry of Health. The opinions of the state council general office on establishing and perfecting the compensation mechanism for the primary health institutions. NO.62 Government Document, 2010.

11. Xiang X, Yang C, Wang D, et al. Effects of China's National Essential Medicines Policy on the use of injection in primary health facilities. J Huazhong Univ Sci Technol 2012;32:626-9.

12. Fang $\mathrm{Y}$, Wagner AK, Yang S, et al. Access to affordable medicines after health reform: evidence from two cross-sectional surveys in Shanxi Province, western China. Lancet 2013;1:227-37.

13. Yang L, Liu C, Ferrier JA, et al. The impact of the National Essential Medicines Policy on prescribing behaviours in primary care facilities in Hubei province of China. Health Policy Plan 2013;28:750-60.

14. Li Y, Ying C, Sufang G, et al. Evaluation, in three provinces, of the introduction and impact of China's National Essential Medicines Scheme. Bull World Health Organ 2013;91:184-94. 
15. Song $Y$, Bian $Y$. Investigation and survey of effects of national essential drug system on township hospitals in Shandong Province and its policy suggestions. China Pharm 2013;24:693-5.

16. Li K, Sun Q, Zuo G. Study of the impact of essential medicine system on the patient visits and cost in township hospital: based on the evaluation method of difference in difference. Chin Health Econ 2012;31:62-4.

17. Gertler PJ, Martinez S, Premand P, et al. Impact evaluation in practice. Washington DC: The World Bank, 2011.

18. Khandker SR, Koolwal GB, et al. Handbook on impact evaluation: quantitative methods and practices. Washington DC: The World Bank, 2010.

19. Hill RC, Griffiths WE, Lim GC. Principles of econometrics. 4th edn. New York: John Wiley and Sons, 2011.

20. Zhang $X$. More measures needed to deepen healthcare reform in China: vice premier. Xinhua English News 30 November 2011. http://news.xinhuanet.com/english2010/china/2011-11/30/c_ 131277817.htm

21. Song Y, Bian Y. Impact evaluation of essential medicine system on prescription charges in township hospitals of Shandong Province. Chin Health Serv Manag 2012;8:586-93.
22. Tian $X$, Song $Y$, Zhang $X$. National essential medicines list and policy practice: a case study of China's health care reform. BMC Health Serv Res 2012;12:401.

23. Ye $\mathrm{Y}, \mathrm{Zhu} \mathrm{L}, \mathrm{Wu} \mathrm{X}$, et al. The effect of the essential medicine policy on the new rural cooperative medical scheme. Chin Rural Health Serv Adm 2011;31:1221-4.

24. Qin J, Zhang Y, Wu N, et al. The impact of performance based income distribution reform to working enthusiasm of health workers. Chin Health Econ 2013;32:71-2.

25. Yan $\mathrm{X}$, Huang $\mathrm{H}$, Xiao $\mathrm{Y}$, et al. The investigation of the current situation on implementing performance related pay of the township health centers in Jiangxi Province. Chin Health Econ 2012;31:71-3.

26. Liang $X$. Practice and experience of deepen reform of performance based salary and related reform in township health centers. Health Econ Res Chin 2013;4:57-9.

27. Lin S. An analysis of the performance-related pay policy of rural township hospitals. J Putian Univ Chin 2012;19:41-5.

28. Lei $X$, Lin W. The new cooperative medical scheme in rural China: does more coverage mean more service and better health? Health Econ 2009;18:S25-46. 